\title{
El erōs de Alcibíades. Entre Sócrates y la philotimia*.
}

The erōs of Alcibíades. Between Socrates and philotimia

\author{
Por: Carolina Modenutti \\ Universidad Nacional del Nordeste \\ Resistencia (Chaco)-Argentina \\ Correo: dcmodenutti@gmail.com
}

Fecha de recepción: 21/02/2019

Fecha de aprobación: 25/03/2019

Resumen: En el presente trabajo nos proponemos abordar el erōs platónico desde la perspectiva que ofrece el relato vivencial de Alcibíades en el Banquete. Deseamos demostrar dos tesis. La primera es que Alcibíades es un timócrata, amante de la fama y los honores, y por tanto es la búsqueda de la timē lo que guía sus acciones. La otra tesis es que la philotimia de Alcibíades es fundamental para complementar la concepción de erōs que presenta el discurso de Sócrates, ya que aporta el componente político, aparentemente dejado de lado en la presentación metafísico/religiosa de este.

Palabras claves: Erōs, Alcibíades, Banquete, philotimia, política.

Abstract: In the present work I intend to approach the Platonic erōs from the perspective offered by Alcibiades' experience in the Symposium. My aim is to demonstrate two theses. In the first place, that Alcibíades is a timocrat, lover of fame

\footnotetext{
* Este artículo forma parte del proceso de producción de tesis doctoral "El éros platónico y las implicancias de su relación con lo político en Banquete y República" bajo la dirección de la Dra. María Angélica Fierro.

* Licenciada en Filosofía (Facultad de Humanidades, Universidad Nacional del Nordeste, Argentina). Doctoranda en el Doctorado en Filosofía (Facultad de Humanidades, Universidad Nacional del Nordeste, Argentina). Docente Filosofía Antigua y Metafísica, Facultad de Humanidades, Universidad Nacional del Nordeste, (Argentina).
} 
and honors, and therefore it is the search for time that guides his actions. Secondly, that the philotimia of Alcibiades is fundamental to complement the conception presented by Socrates' speech on erōs, since it provides the political component, apparently left aside in its metaphysical/religious presentation. Key words: Erōs, Alcibíades, Symposium, philotimia, politics.

\section{Cómo citar este artículo:}

APA: Modenutti, C. (2019). El eros de Alcibíades. Entre Sócrates y la philotimia. Nuevo Itinerario, 14 (1), 111-137. Recuperado de: (agregar dirección web)

\section{Introducción}

La intervención de Alcibíades en el Banquete platónico (212d4-223a10) resulta a todas luces muy atractiva para ser analizada debido a su tono discordante con todos los discursos anteriores los cuales, una vez terminada la comida y los ritos subsiguientes, siguen la consigna de Erixímaco y se dedican a elogiar a $\operatorname{Erōs}^{1}$ (177d3-5); pero, fundamentalmente, resulta contrapuesta al carácter religioso/metafísico de la visión suprema -ta telea, ta epoptika- (209e8-210a1) que Diotima revela a Sócrates².

${ }^{1}$ El Banquete está dedicado a Erōs, dios del amor, y a medida que cada participante va exponiendo quién es este dios, va dando cuenta de qué es erōs en tanto pasión o sentimiento amoroso. Este término es complejo de traducir y se ve muy parcialmente reflejado en la moderna palabra amor, que en griego refiere a cuatro términos diferentes: agape (amor al prójimo independiente de la reciprocidad) philia (amor recíproco que incluye afecto sereno, estabilidad y benevolencia), storge (amor filial, que implica cariño y ternura) y erōs (deseo amoroso que aspira a la unión carnal) (Álvarez Lacruz, 2006). Para evitar confusiones a lo largo del escrito optamos por utilizar el término griego erōs sin traducción.

${ }^{2}$ Las palabras de Diotima hacen referencias constantes al plano religioso mediante la utilización de expresiones como "iniciado" (209e7-8), "revelación última" (209e8), posibilidad de "inmortalidad" (212a9) (también encontradas en el segundo discurso de Sócrates en Fedro); específicamente, los términos ta telea (lo perfecto) y ta epoptika (lo visto, las visiones) remiten al culto de Eleusis, culto mistérico e iniciático, que permite a los hombres llegar a una nueva forma de existencia a partir de una revelación (Eggers Lann, 2000; Guthrie,1984). Esta terminología, combinada con la propuesta platónica de culminación del proceso amoroso con la contemplación de la Belleza en sí, dan el carácter religioso/metafísico al que estamos refiriendo. Según Conford (1974) la complementación entre el estado cognitivo al que se aspira y la transformación anímica necesaria para alcanzarlo es lo que conjuga lo religioso con 
En lugar de encomiar al dios o tratar de explicar su naturaleza, Alcibíades anuncia que va a elogiar a Sócrates $(214 \mathrm{~d} 8)$ y lo hará mediante el relato de su propia experiencia amorosa con él, ocasión de la que también se sirve para vengarse de su maestro por los agravios padecidos (214e2). Esta manera diferente de exponer sus ideas acerca de erōs mediante un relato vivencial que mezcla elogio y crítica, sumada a toda la escena dramática que lo acompaña, ha llevado al debate de muchos intérpretes sobre el motivo de su inclusión en el diálogo y sobre el significado de sus palabras ${ }^{3}$, quienes, aunque desde perspectivas diferentes, suelen coincidir valorar las palabras de Alcibíades a partir del parámetro de la escala amorosa propuesta por Diotima (210a212b). Según la sacerdotisa, quien logre identificar la uniformidad ${ }^{4}$ de la belleza (kallon) en sus diferentes manifestaciones, que ascienden desde los cuerpos, hábitos de vida, normas y conocimientos bellos, hasta lo bello en sí (211 c1-9), será amado por los dioses e incluso inmortal (212a7-9). Erōs entonces es el facilitador para que los seres humanos entren contacto con aquello que es bello siempre, que existe en sí, por sí y para sí y del que todas las otras cosas bellas participan (211b1-3) y, de esta manera, puedan devenir inmortales, cualidad en esencia privativa de los dioses.

Siguiendo la descripción de Alcibíades, sin lugar a dudas Sócrates encarna al iniciado en los misterios de Erōs, por ser amante de la sabiduría y capaz de controlar sus instintos (219d-221b) a partir de la sublimación correcta de los deseos, esto es, por la predominancia de la razón (logos) sobre los apetitos (epithymiai) y la impulsividad

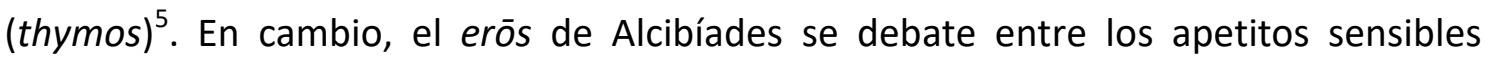

lo metafísico: "tal vez la experiencia de Platón debería ser llamada metafísica más que religiosa, o sea, reconocimiento de la última verdad. Por otra parte, no se trata de algo puramente intelectual, sino de una conversión de todos los elementos del alma en virtud de la última transfiguración de Erōs: y en este punto la distinción entre lo metafísico y lo religioso puede ya perder sentido" (p. 143).

${ }^{3}$ Vid. Rowe (1998); Soares (2009); Nussbaum (1995); Strauss (2001).

${ }^{4}$ El supuesto en la argumentación socrática es que la belleza que es objeto de erōs, a pesar de manifestarse de diferentes maneras y en diferentes cantidades, es una, idéntica en su género. Por eso, como sostiene Nussbaum (1995), "en la explicación sobre el desarrollo del alma hacia el saber pleno del bien, la idea de uniformidad desempeña una función esencial" ( $p$. 246).

${ }^{5}$ Si bien en Banquete no hay un desarrollo explícito de la psicología platónica, sí podemos encontrar ideas que congenian con lo expuesto en diálogos como Fedro y República 
(epithymiai) y el deseo de éxito (philonikia) y de honor (philotimia), aunque si consideramos con atención sus palabras, podemos inferir que son los deseos de fama y honores los que realmente se imponen en su espíritu. En este sentido, la aspiración de Alcibíades a la sabiduría es débil (Vid. Rep. 6.485d7-9) o quizás inexistente pero eso no impide que haya en él un deseo de inmortalidad, no la divina que se alcanza con el conocimiento verdadero (epistēmē), sino una más terrenal que se consigue con el renombre y el honor (timē). Este deseo de inmortalidad de tipo terrenal también es considerado por Diotima (208c1 a 209e4) y es el que se consigue al engendrar discursos sobre la virtud (209b8), poesías (209a4-5, 209c7-d4) y leyes para regular las ciudades (209a6-8, 209d4-e4), todos estos productos de hombres virtuosos en búsqueda de fama inmortal. Propio de poetas, artesanos, legisladores y políticos este deseo está regido por la philotimian (208c3) y la virtud es un medio para alcanzarla.

A partir de estos dos tipos de deseo de inmortalidad, divina y terrenal, que aparecen como definición de erōs en el discurso de Diotima, nos preguntamos: la philotimia que manifiesta Alcibíades, ¿es necesariamente negativa, es decir, un obstáculo o desvío del verdadero objeto erótico, o incompleta, como un deseo que se queda a mitad del recorrido y no llega a la meta del deseo de lo en sí? 0 , por el contrario, ¿puede el erōs de Alcibíades aportar algo novedoso a la concepción del amor platónico en su inclinación a la philotimia y no a la philosophia? Lo que pretendemos demostrar en el presente artículo es que el erōs de Alcibíades retratado en el Banquete reviste una importancia fundamental en la comprensión de la erótica platónica porque lo vincula explícitamente con la cuestión política. Alcibíades se presenta como un enamorado de Sócrates y a la vez como un amante de los honores, lo cual, lejos de resultar algo negativo para la verdadera erótica, recuerda al amante de

en lo referente al dominio de sí mismo. En los diálogos mencionados bajo el supuesto de la tripartición de las tendencias anímicas (sabiduría, apetitos y honores), es necesario que la razón controle a las partes apetitiva e irascible. En los hombres que logran este ordenamiento psíquico "entonces, sin duda, si triunfan los mejores elementos de la mente, conduciendo a una vida ordenada y al amor de la sabiduría, ellos pasan la vida de aquí en dicha y concordia, dueños de sí mismos y mesurados, porque han sometido a esclavitud aquello que engendraba la maldad del alma, y puesto en libertad aquello que producía la virtud" (Fdr. $256 a-b$ ). "Y sabio se ha de llamar por aquella pequeña parte que mandaba tales cosas, poseyendo en sí misma, a su vez, el conocimiento de lo que es provechoso para cada una y para la comunidad que integran las tres" (Rep. 4. 442c5-8). 
la verdad la importancia de la consideración de los otros, o de lo político, en el proceso.

Para lograr este objetivo primero abordamos la noción de erōs en el Banquete tal como la presenta el discurso de Sócrates/Diotima, que de alguna manera responde a todos los anteriores oradores, y que permite una consideración amplia y versátil de la erótica. Luego mostramos cómo el erōs de Alcibíades, considerado a partir del discurso Sócrates/Diotima, puede tener una doble interpretación: en la primera puede ser leído como el incumplimiento del ascenso amoroso que permitiría conocer la Idea de Belleza, siendo Alcibíades el "amante erótico a medio camino" (Boeri, 2010); en la segunda, se considera que Alcibíades, en tanto amante de los honores, no es un mal amante, o un amante a medio camino sino solo un amante diferente, un amante político, cuyo objeto de deseo es el reconocimiento de los demás y que, por este motivo, puede colaborar con una concepción del erōs platónico que articule filosofía y política.

Elementos para definir a erōs en el discurso de Sócrates: dynamis, metaxy y la aspiración a la inmortalidad.

El discurso de Sócrates, primero en diálogo con Agatón (199c5-201c10) y luego con Diotima (201d1-212a9), y en concordancia con todos los discursos anteriores del Banquete, trata de explicar quién es Erōs como divinidad para poder entender qué es erōs en tanto pasión erótica, dejando en evidencia que pretender una conceptualización inmediata del dios o de la pasión es una tarea compleja, puesto que no se trata de una entidad con cualidades acabadas ni tampoco de una naturaleza definida que podamos ubicar dentro de los esquemas más comunes de mortal o divino, bello o feo, etc. Respecto a quién es Erōs, según Diotima no puede ser concebido como un dios porque, por su naturaleza, no es bello sino que va en búsqueda de lo bello y todos los dioses, por definición, son dichosos y bellos (202c4-6); Erōs más bien es un daimōn, un ser intermedio-metaxy- entre lo mortal y lo divino (202d10-12) y en consecuencia también se ubica en un lugar intermedio respecto a: a) 
los valores que tensionan entre su estado y lo que desea alcanzar; b) al conocimiento que posee, y c) sus posibilidades para conseguir aquello de lo que carece. Por un lado, se ubica en un lugar intermedio entre lo bueno y lo malo, y lo bello y lo feo (202 b2-4); desea algo que él no es y de cual está falto (200e4-5), lo bello y lo bueno ${ }^{6}$, pero eso no lo hace ser necesariamente su opuesto, malo y feo, cosa que no sería compatible con la naturaleza de una divinidad. Por otro lado, Erōs está en el medio de la sabiduría y la ignorancia (203e6), desea poseer la sabiduría, considerada por Platón una de las cosas más bellas, pero el acto mismo de desear el saber da cuenta de que no se encuentra en estado de ignorancia absoluta, sino de esa ignorancia del saber que no se sabe y que motiva a la búsqueda; es por esto que Erōs es filósofo (204b4), consciente de su carencia y amante de la sabiduría. Y, por último, el origen mítico que Diotima atribuye a Erōs explica su condición metaxy, que como hijo de Pobreza (Penia) y Recurso (Poros), es por descendencia materna pobre, carente y de mal aspecto, pero gracias a su descendencia paterna, siempre está al acecho de lo bello y lo bueno y cuenta con ingeniosos recursos para conseguirlo (203c7-d6).

La condición intermedia entre lo bello y lo feo, la sabiduría y la ignorancia, el recurso y la carencia otorga a este daimōn la capacidad de hacer posible un diálogo entre dioses y hombres (203a3-4), esto es, la capacidad de vincular dos planos que ontológicamente se encuentran separados, el humano, finito e imperfecto, con el divino y eterno, convirtiéndose en un colaborador para que nos volvamos semejantes a los dioses lo más que nos sea posible (Fierro, 2007) ${ }^{7}$. Erōs en realidad, nos dice Diotima, más que el deseo de las cosas bellas, es deseo de engendrar, de dar a luz en

${ }^{6}$ En 204d Diotima sustituye el objeto de erōs hasta el momento fijado como lo bello (to kallon) por lo bueno (to agathon). Nosotros no vamos a detenernos en esta distinción ya que esta discusión escapa a los límites de nuestro trabajo. Para la relación entre to kallon y to agathon en este punto puede consultarse Jaeger (1942), Strauss (2001), Rowe (1998).

${ }^{7}$ Esta facultad nominada con el término metaxy implica una utilización diferente del término dentro de los usos regulares dados por Platón en otros diálogos lo cual resulta importante en la medida en que brinda a la condición intermedia el carácter de potencia; "lo nuevo en el significado de metaxy en el Banquete tiene que ver entonces con que Erōs es impulso hacia, en este caso, la belleza (cuya expresión máxima es la Belleza en sí), vinculando entonces lo humano, asociado a lo perecedero, con un principio absoluto, divino y eterno, siendo así un colaborador esencial para que nos volvamos semejantes al dios lo más que nos sea posible" (Fierro, 2007, p.254). 
lo bello (206e3-5) y lograr de este modo la inmortalidad. Como sostiene Conford (1974), "el fin no es el goce individual e inmediato de la belleza, sino la perpetuación de la vida por medio de un acto creador al que asiste la Belleza como una diosa del nacer, para dar descanso a los afanes. La procreación es el atributo divino del animal que muere. Erōs es, en última instancia, el deseo de inmortalidad" (p. 137). Y esta inmortalidad es lo que permite equiparar a los seres humanos con los dioses.

Sin embargo, en las palabras de Diotima que explican los misterios de erōs encontramos dos tipos de inmortalidad ${ }^{8}$. Una es la que consiste en perpetuarse en el tiempo y en este sentido es una inmortalidad terrenal que se logra engendrando belleza en cosas terrenales y subsistiendo de esta forma en la memoria colectiva de un pueblo o comunidad. Quien engendra sabiduría y virtudes, como los poetas, artesanos inventores de oficios y legisladores (209 a), desde temprana edad busca acercarse a los que están dotados de belleza física y anímica, porque "frente a esta persona [bella de cuerpo y alma] inmediatamente se colma de discursos acerca de la virtud y de cómo debe conducirse el hombre noble y en qué debe ocuparse, e intenta educarla" (209b6c1). La virtud de los poetas y legisladores queda plasmada en discursos, la poesía (209a4-5, 209c7-d4) y la ley (209a6-8, 209d4-e4), y estos hombres logran inmortalizarse por medio del eterno renombre. En este caso, el genuino deseo de los amantes es el reconocimiento y fama (philotimia) y la virtud que les permite engendrar en la belleza funciona como un medio para alcanzarla (Larsen, 2013). En otras palabras, por más que estos hombres sean virtuosos, el contacto con la belleza es buscado en pos del reconocimiento de los demás, quedando así atrapados en plano de lo terrenal. El efecto de este erōs es una inmortalidad que consiste en perdurar en el tiempo infinitamente, pero no alcanzar la eternidad (Ludueña, 2015), esto es, el contacto con lo que está fuera de los parámetros temporales, y, en consecuencia, fuera de todos los parámetros que miden o regulan lo sensible, material y humano. Es por ello que el erōs del filósofo es el deseo de la inmortalidad divina que se ubica fuera

${ }^{8}$ Sobre la distinción entre inmortalidad divina y terrenal: Conford, 1974; Guthrie, 1990; Soares, 2009. 
del tiempo, en la región de lo eterno alcanzada por el contacto inmediato con la Idea y que convierte al hombre en inmortal en el sentido divino (Conford, 1974).

Ahora bien, la Belleza parece constituir más un horizonte regulativo para orientar la búsqueda erótico-filosófica que una posibilidad real de ser alcanzada (Soares, 2009) pues para llegar a contemplarla es necesaria una preparación superior que ni siquiera Sócrates parece tenerla (209e6-9) y, además, el caso en que se produzca pareciera ser una eventualidad $(211 \mathrm{~d} 4)^{9}$. Por lo cual, la inmortalidad divina tiene considerablemente menos posibilidades de concretarse que la inmortalidad terrenal.

En cuanto a qué es erōs, según el acuerdo al que llegan Sócrates y Agatón, su nota más saliente es que siempre resulta ser deseo o tensión de algo y de algo que le falta (200e9-10), carencia que no implica que su objeto de deseo esté predeterminado, o lo que es igual, no implica que todos deseemos lo mismo. El deseo erótico es deseo de lo bueno y como "los dichosos son dichosos porque poseen lo bueno" (205a2), el hecho de desear es común a todos los seres humanos (205a7-9), en último término todos buscamos la felicidad. ${ }^{10}$ La universalidad del deseo erótico va de la mano con su

${ }^{9}$ Este carácter regulativo de las Ideas también podemos hallarlo República, donde el Bien en sí es una entidad del plano eidético que, por tanto, reviste superioridad y trascendencia respecto a todo lo que pueda considerarse como bueno en el plano de las acciones humanas. Sin embargo, la Forma de Bien, como el Estado ideal nunca se alcanzan en términos prácticos, sino que tienen que funcionar como un modelo al que se tienda permanentemente y regule las acciones humanas. Siguiendo a Boeri (2007), "...la Forma de Bien como cualquier otra Forma tiene un "carácter regulativo", por cuanto, sin ser un ingrediente que pueda constituir nuestro mundo "real" -en el sentido de que es imposible aplicar el modelo a cualquier cosa dada de nuestra experiencia fenoménica-, resulta imprescindible para mostrarnos que el logro del paradigma constituye un trabajo constante y algo a lo cual siempre hay que aspirar" (p. 81). En la misma línea, Soares (2010) sostiene que la aprehensión de este principio inteligible permite a los guardianes perfectos del Estado determinar qué es lo realmente bueno para la polis y, de esta manera, garantizar la felicidad pública y privada de todos sus habitantes. Más que fundamento ontológico de la realidad la Idea de Bien es el principio regulador del orden ético político del Estado.

${ }^{10}$ Rowe (1998) considera que esta presentación del erōs como deseo de felicidad por parte de Diotima en los llamados "misterios menores" (204d1-209e4) no es del todo seria, porque presenta al erōs sexual en todas sus manifestaciones como expresión de un deseo universal de felicidad. Sin embargo, según los "misterios mayores" (210a-212c) no es posible alcanzar alguna cosa que responda a nuestro deseo del bien antes de adquirir la verdadera comprensión de lo bueno, la phronēsis. 
neutralidad, desear no tiene valor positivo o negativo en sí mismo, este valor lo determinará el objeto al que se dirija (Conford, 1974) que, como dijimos, no es el mismo para todos. Debido a una reducción errónea, no a todos los que desean los llamamos amantes porque "ocurre que separamos una especie del erōs y, aplicándole el nombre del todo, la llamamos "erōs ", mientras que para referirnos a las demás especies del erōs utilizamos otros nombres" (205b3-6); sin embargo, todos los seres humanos somos amantes/deseantes de lo bueno, aunque lo busquemos en distintas direcciones, (unos en el afán de gastar dinero, otros en el amor a la gimnasia, otros en el deseo de sabiduría $(205 d 3-6)$ y, en este sentido, lleguemos a él de diferentes maneras.

Como sostiene Borges de Araujo Jr. erōs es una dynamis, una potencia o una "capacidad de", que se define por la relación que establece con los objetos y por los efectos que produce en esta relación (Borges de Araujo Jr., 2012). Entonces, siendo más precisos, los objetos deseados, sean estos otros cuerpos, el dinero, los placeres, la fama, etc. tampoco son portadores de una carga valorativa en sí mismos, sino que para ser juzgados como positivos o negativos, siempre poniendo de referencia al sujeto deseante, dependen de los efectos que produzcan en él. No obstante, no es indiferente la elección del objeto de deseo porque la relación de Erōs con cada uno de ellos en cada caso produce efectos diferentes o diferentes tipos de amor. "Cuando cambia la orientación, Erōs, como una dynamis, transforma también el efecto que produce en el corazón de los hombres" (Ibíd, p. 26). Así, la forma de vida y las acciones de un amante de la sabiduría no será la misma que la de un amante de los honores o de un amante de los placeres.

Si bien erōs es una dynamis que puede dirigirse a cualquier objeto, el verdadero o el que produce la verdadera felicidad es el que se alcanza en la culminación del ascenso erótico, el contacto con la Idea de Belleza. Es por esto que el deseo debe ser educado para que se dirija, superando diferentes instancias, exclusivamente a lo Bello en sí; “...en el discurso de Sócrates la instrucción filosófica deviene, bajo la guía de 
Diotima, en una paideia del deseo basada en una iniciación que procura orientar el impulso erótico en un sentido ascendente por los distintos grados o dimensiones de la belleza: sensible (belleza de un solo cuerpo y de todos los cuerpos), espiritual (belleza del alma), ético-política (belleza de las normas de conducta), epistemológica (belleza de las ciencias) y metafísico-religiosa (Belleza en sí)" (Soares, 2009, pp. 96-97). El núcleo del discurso de Sócrates/Diotima podría resumirse en un reconocimiento de la homogeneidad o uniformidad de la belleza en sus diferentes manifestaciones previas (Nussbaum, 1995) a la contemplación de lo bello en sí, que requiere de los amantes un trabajo sobre sí mismos para educar el deseo y así para dirigir sus esfuerzos y energías hacia el objeto verdadero.

Esto deriva en dos cuestiones que es importante señalar. La primera es que la Belleza como objeto de la erótica no quita de escena a los otros sujetos, es decir, la erótica que propone Platón según el modelo de la relación entre Sócrates y Alcibíades que estamos analizando aquí, no es nada más que la relación de un sujeto con la Idea, simplemente se produce una modificación de los roles clásicos de amado (erōmenos) y amante (erastēs), coincidentes con los lugares de pasivo y activo (Foucault, 2008; Dover, 2008; Calame, 2002) y las diferencias en cuanto status se disuelven en la medida en que ambos participantes de la relación devienen sujetos deseantes/ amantes con respecto al objeto en cuestión (Foucault, 2008). Esto es lo que Alcibíades reclama una y otra vez a Sócrates, el intercambio o la imprecisión de los papeles de amante y amado (221d;222b) y por lo que buscará vengarse (213e), por lo que su discurso es un elogio a Sócrates por sus cualidades virtuosas a la vez que una venganza por el destrato padecido (214e). Sin embargo, este cambio de roles, lejos de resultar un problema, tal como lo siente Alcibíades, es la clave para reinterpretar la relación con el amado que deja de ser concebido como objeto que al alcanzarlo nos llena o complementa y se lo reconoce también él como sujeto faltante y deseante (Fierro, 2006). La relación con Sócrates, un amante de la sabiduría que refleja en su propio ser y existir esta condición, permite a Alcibíades reconocer que su belleza física y los bienes mundanos, plagados de particularidad y materialidad, que posee, no tienen valor alguno comparado con lo bello en sí. 
En relación con esto, la segunda cuestión que queremos señalar tiene que ver con las diferencias en cuanto al objeto y a la forma de amor que pueden presentar los amantes en la experiencia amorosa y que resulta evidente en la relación de Sócrates y Alcibíades. Según el relato del político ateniense, la dynamis de Sócrates se orienta hacia la sabiduría gracias al dominio que tiene sobre sí, es decir, el control que tiene el aspecto racional de su alma sobre la parte impulsiva y la parte apetitiva. Este autocontrol produce que, sin anular el deseo hacia Alcibíades y otros bellos muchachos, Sócrates pueda reconocer la parcialidad de la belleza física de estos y contener sus apetitos en búsqueda de una belleza más estable y completa. El efecto de una dynamis orientada a la verdad es el desarrollo de la virtud personal. En cambio, el deseo de Alcibíades parece estar en una dirección diferente, pero que no resulta del todo clara; declara haber estado intensamente enamorado de Sócrates, lo cual podría indicar la naturaleza filosófica de su alma que lo impulsa a acercarse a quién lo puede encaminar a la consecución de la verdad, pero en la escena relatada en el Banquete, también se muestra que este amor no ha logrado apartarlo del impulso hacia las epithymiai sin ningún tipo de control, retratados en su borrachera, su desenfreno erótico, etc. A la vez, el político ateniense, posiblemente por esta misma condición de político, se muestra como un ser débil ante el reconocimiento y los honores que le dispensan los demás.

De manera que el amor de Alcibíades puede ser analizado desde dos perspectivas: la primera es interpretarlo como el incumplimiento del ascenso amoroso que conduce hasta la Idea de Belleza, según la cual éste sería el amante erótico a medio camino que tiene una naturaleza buena pero se deja llevar por las epithymiai y termina siendo un tirano. La segunda opción, que es la que intentaremos fundamentar en las siguientes páginas, es considerar a Alcibíades, a partir de su condición natural de político, como un amante de los honores, lo cual no lo hace necesariamente un mal amante o un amante a medio camino, sino más bien un poseedor de un tipo de deseo que puede articularse con el del amante de la sabiduría para completarlo. 


\section{Alcibíades y su amor desenfrenado}

Alcibíades fue un destacado político de Grecia, principalmente en el momento histórico en el que Platón sitúa el relato de Banquete (416 a.C.), ${ }^{11}$ aunque su protagonismo estaba teñido de aciertos y errores, de alianzas y enemistades con el pueblo ateniense, posiblemente, producto de su singular personalidad. Historiadores antiguos y contemporáneos retratan a este general como una figura que se destaca por su inteligencia, carisma y habilidad para la política, pero que como contraparte de estas virtudes lleva una vida plagada de excesos, vicios y placeres apetitivos ${ }^{12}$. Extendida al ámbito de su labor política, la desmesura de sus apetitos lo llevaron a anteponer las aspiraciones personales por sobre el bienestar de la ciudad; así lo señala Asimov (1996) en referencia al episodio en el cual Alcibíades logró convencer al pueblo ateniense de embarcarse en la expedición a Sicilia en el 415 a. $C^{13}$ : "era rico, bello, inteligente y encantador, pero carecía totalmente de escrúpulos. Estaba ansioso de llevar a cabo grandes hazañas, y para ello necesitaba la guerra. Siguiendo sus propios

${ }^{11}$ La fecha del relato (no de la composición) del Banquete es determinada por el año del triunfo de Agatón en Leneas, según un pasaje de Ateneo.

${ }^{12}$ Nuestro interés en estas líneas no es realizar una descripción del Alcibíades histórico, sino simplemente de brindar una imagen de su personalidad que luego se verá reflejada en el personaje que presenta Platón en Banquete, por lo que nuestras referencias a su vida y los hechos que protagonizó son acotadas y generales. Para un abordaje histórico de Alcibíades se pueden consultar, entre las fuentes antiguas a Tucídides Historia de la guerra del Peloponeso; Plutarco Vidas paralelas y Cornelio Nepote Vidas de los más famosos generales griegos y cartagineses...; Y entre las fuentes contemporáneas a Asimov, I. Los griegos. Una aventura; De Romilly, J. Alcibíades.

${ }^{13}$ En 415 a.C. zarpó la expedición que daría inicio al proyecto concebido por Alcibíades de crear un Imperio ateniense tomando Sicilia e Italia, que había logrado entusiasmar al pueblo y generar confianza en él. Pero casi al mismo tiempo tuvo lugar el episodio de los Hermocópidas cuyo principal acusado fue Alcibíades. Luego de esto se alió con Esparta enfrentándose a los atenienses, pero al tiempo volvió a pelear con ellos (407 a.C.). En el 406 a.C. nuevamente fue acusado de traición por pactar con los espartanos y tuvo que huir. Finalmente, murió asesinado en territorio persa en el 404 a.C. 
deseos no vaciló un momento en lanzar nuevamente a Atenas a una guerra que no necesitaba ni deseaba" (p.81). A partir de este hecho y del episodio de los Hermocópidas que tuvo lugar unos días antes de que zarpara la expedición, queda al descubierto la ambivalencia que atraviesa la figura de Alcibíades puesto que la inteligencia (dianoia) y sagacidad de las que se valió para embarcar a los atenienses en esta empresa, convive con la insensatez (anoia) y falta de previsión (pronoia) que implicaba un plan de este tipo para una Atenas sin los recursos económicos y militares necesarios, y la transgresión a las normas (paranomia) religiosas y políticas en la mutilación de los Hermes (Bieda, 2016).

Los rasgos tan controvertidos de esta personalidad son recogidos en el personaje de Alcibíades que Platón construye en el Banquete ${ }^{14}$. Este hombre débil ante el reconocimiento que le dispensa el vulgo (216b5-6), se presenta ebrio, a los gritos y disfrazado con una corona de hiedras y violetas y cintas colgantes (212d4-e2) ${ }^{15}$, causando la risa de los convidados (212e10-11) no solo por su estado sino también porque los reproches que lanza contra Sócrates, que los veremos en las siguientes líneas, hacen parecer que todavía estaba enamorado de él (222c1-3). Las palabras que Alcibíades dedica a Sócrates son intensas, apasionadas y cargadas de emotividad; reproches, exposición de situaciones íntimas, contradicciones se expresan en a los gritos, en tono de reclamo, pidiendo el asentimiento de otros, buscando el protagonismo y la mirada de los asistentes declarándose "árbitro de la bebida" (213e13). La primera acusación de Alcibíades es la supuesta persecución constante de Sócrates "otra vez preparándome una emboscada; tal y como cuando acostumbrabas a

${ }^{14}$ Diferentes autores fundamentan el vínculo existente entre el diálogo platónico y el Alcibíades histórico: Cornelli (2012); Centrone (1999); Giá Gomperz (1905); Robin (1908).

${ }^{15}$ Incluso no es solo el contenido de su discurso lo que da cuenta del carácter pasional del personaje, sino que, además, hay una serie de elementos que rodean la escena que enfatizan la carga pasional/emotiva del drama. Así lo demuestran su aparición sin invitación, en estado de ebriedad, a los gritos y teniendo que ser sostenido por una flautita y sirvientes (212e). Además, su atuendo era también del todo llamativo y simbólico. Llevaba puesta una corona de hiedras y violetas y con cintas colgando(212e1-2). Las violetas lo presentan como afeminado (ya que es signo de la divinidad femenina Afrodita) y como poeta que dice la verdad con imágenes y símiles (ya que es utilizada por las Musas). Además, se puede interpretar un juego de analogía con la democracia de Atenas que, como Alcibíades se encuentra a merced de la fortuna y las pasiones irracionales (Nussbaum, 1995). 
aparecer de pronto allí donde yo menos te esperaba" (213c1-2), pero que Sócrates inmediatamente refuta afirmando que es Alcibíades quien, producto de su amor movido por los celos y la envidia, no le da libertad y al que tiene "...pavor de su locura (mania), de sus tremendas ganas de ser amado (philerastia)" (213d7-8). Por eso, aunque el relato cuenta una relación que tuvo lugar en el pasado cuando finaliza, Alcibíades todavía parece enamorado de Sócrates o, al menos, eso es lo que notan los demás comensales (222c1-3).

En la siguiente y principal acusación, Alcibíades sostiene que Sócrates lo convenció de iniciar una relación pedagógico/amorosa ${ }^{16}$ pero luego no dio lugar a la satisfacción de sus deseos sexuales ${ }^{17}$, evitándolo en toda ocasión en la que se disponía a intimar con él (217b3-219e1). Es por esto que siente la necesidad de contar su desventura amorosa y de advertir a otros, especialmente a Agatón, para que no se deje llevar por los engaños de Sócrates; "no aprendas como el tonto, que aprendió sufriendo" (222b9-10). Cabe preguntarnos si la concreción del acto sexual era tan importante para Alcibíades o más bien lo que lo inquietaba y no podía tolerar era la indiferencia ante su belleza física y carisma que atraía a tantos amantes y provocaba la estima de los atenienses. Si consideramos que, tal como señala Sócrates (213d6), la synousia (unión, estar juntos) que propone Alcibíades es philerastia (ansia o afición amorosa) ${ }^{18}$ su erōs no es genuino porque no puede mediatizar el deseo sexual (Boeri, 2016) y el contacto carnal deviene un componente central para la relación. Esta synousia (estar juntos) como philerastia no solo pone en primer plano el placer sexual,

\footnotetext{
${ }^{16}$ Hay diferentes referencias de la relación de Sócrates con Alcibíades pero que coinciden en reconocer el vínculo amoroso/político entre ambos. En Alcibíades I de Platón, Sócrates se acerca a Alcibíades por mandato del dios, y es quien va a acompañar a Alcibíades (que tiene menos de 20años) en la preparación en la virtud para el ejercicio del gobierno. En Recuerdos de Sócrates Jenofonte sugiere que la relación de Alcibíades con Sócrates está basada en la conveniencia consiente que para un futuro político significaba ser discípulo de Sócrates. Pareciera que Alcibíades, ambicioso de poder y convencido de sus metas, encontraba en Sócrates más que un maestro del alma, una seguridad para el éxito de su vida política, cuyo ingreso estaba asegurado por su estatus. De manera que, sea como cuenta Platón que Sócrates busca a Alcibíades cuando el dios se lo indica o como dice Jenofonte que Alcibíades se acerca a Sócrates por conveniencia, la relación de amor se basa en una necesidad política.

${ }^{17}$ Para las particularidades que implicaban las relaciones pedagógicas en la Antigua Grecia, se puede consultar Marrou H.E. (1971) Dover, K. (1978).

18 La philerastia como vinculo exclusivamente sexual aparece previamente en el discurso de Aristófanes 196c. Vid. Rowe, 1998, Dover, 1980.
} 
sino que además está contaminada de todos los vicios de las relaciones propiamente humanas: el enojo y la venganza (213d9-11), la perturbación que le producen las palabras de Sócrates que aceleran su corazón y lo llevan al Ilanto (215d12-e1-2), el amor y odio coexistentes (216c1-4), el orgullo que pretende que hacer ver a Sócrates como el interesado en concretar los deseos sexuales y no a él mismo (218c1-d1), evidencian todos los conflictos que le produce al enamorado quedarse en el primer peldaño de la escala amorosa ${ }^{19}$, atado a un cuerpo y a un individuo.

Sin embargo, si bien podemos suponer que en el contexto del diálogo, el deseo sexual no carece de importancia, puesto que saciarlo implica generar una intimidad entre los amantes que puede favorecer al desarrollo del saber intelectual que busca la erótica, para que esto suceda, el acto sexual en sí mismo no es necesario (Nussbaum, 1995). Lo fundamental es la apertura de los amantes para la reciprocidad en el contacto físico y en el conocimiento intelectual y práctico. En este sentido, Alcibíades es un erōmenos poco apropiado, o mal amante, porque la vanidad y autosuficiencia que le inspira su belleza impiden que se abra, que se vuelva un objeto del mundo de la actividad del otro y del mundo del acontecer general que afecta en sus relaciones con el otro (ibíd.).

Desde la perspectiva de Alcibíades es Sócrates el ensimismado para quien cualquier atributo que el resto de los mortales consideraría digno de estima y motivo para ceder ante ellos, para él no lo es:

sepan que para nada le interesa si uno es bello-nadie creería hasta qué punto desprecia esto-, ni si uno es rico, ni si posee ningún otro atributo de eso que la mayoría considera envidiables. Entiende que todas esas posesiones no tienen valor alguno y que nosotros no somos nada, lo aseguro. (216d9-e5).

${ }^{19}$ Para Boeri (2016), mediante las figuras de Sócrates y Alcibíades, Platón refleja su tesis de que Erōs se compone de lo humano y lo divino, de lo mortal e inmortal, consecuencia de su naturaleza metaxy, intermedia e intermediaria; pero las bellezas física y anímica no están en el mismo nivel, “... el erōs socrático no elimina sin más los ingredientes corpóreos del deseo erótico (Sócrates desea a Alcibíades), pero sabe que la belleza más firme o más real es la anímica, no la corpórea"(p. 369). La belleza física de Alcibíades y su erótica enraizada en lo corporal, no es suficiente porque no es duradera y permanente. 
El reclamo parece dirigirse a la falta de reconocimiento de su valor personal producto de sus atributos físicos, estatus social y político, de sus riquezas, más que a la negativa de acceder al acto sexual. Sócrates es capaz de notar todo esto en el general ateniense, pero también es capaz de jerarquizar las formas en que la belleza se manifiesta y la ventaja que representa su propia belleza anímica con respecto a estas, por eso sostiene con firmeza:

Ciertamente has de estar viendo en mí una belleza extraordinaria y del todo diferente a la belleza de tu figura. Y si al advertirla pretendes hacer un acuerdo conmigo y cambiar belleza por belleza, no poca ventaja piensas sacar de mí; sino que pretendes quedarte con algo verdaderamente bello a cambio de algo que solo lo es en apariencia. En verdad planeas cambiar 'oro por bronce'... (218e3-10)

El problema con esta desestimación de la parcialidad de la belleza terrenal es que también conlleva desestimar a los individuos portadores de ella; tal como sostiene la conocida tesis de Vlastos (1981) el amor de Sócrates no contempla a las personas en su integridad, con sus aspectos buenos y agradables y los aspectos contrarios, sino que se dirige solamente a sus mejores cualidades, resultando un deseo muy alejado de los seres humanos por su imposibilidad de concreción. De manera que aquello que hace virtuoso a Sócrates también lo lleva a alejarse de los seres humanos concretos.

Alcibíades entonces se encuentra en medio de una contradicción, porque se da cuenta del desprecio sufrido “...pero, a la vez, admiraba la naturaleza de este hombre, su templanza y valentía, pues había dado con un ser humano tal como nunca hubiera esperado encontrar en lo que hace a sabiduría y dominio de sí" (219d3-e1). Esto, más que una contradicción interna, resulta una capacidad de apreciar la ambivalencia que produce el erōs socrático en él que oscila entre el amor y la admiración y el odio y el reproche, y quedar él también en una condición amorosa ambivalente entre la conciencia del valor de amar a Sócrates por sus virtudes y el dolor por su vanidad sexual herida. Alcibíades es un "filósofo erótico a mitad camino" (Boeri, 2016), capaz de apreciar el valor de la belleza anímica, producto de la moderación y autocontrol, 


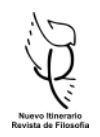

pero incapaz de contener su instinto sexual o, mejor dicho, incapaz de tolerar el rechazo para la satisfacción de sus apetitos sexuales.

\section{Alcibíades y la philotimia}

La psicología platónica desarrollada en República distingue tres aspectos o funciones en el alma humana: to logistikon (razón, cálculo, fundamento, capacidad argumentativa) es aquello por lo cual el alma razona y puede distinguir lo correcto de lo incorrecto, lo bueno de lo malo, to epithymetikon (apetito o deseo corporal y primario) aquello por lo cual el alma ama, tiene sed y es excitada por todos los apetitos irracionales vinculados a las satisfacciones sensuales y al placer en general (4. 439d611) y to thymoeides (fogosidad, cólera, impulsividad) es aquello por lo cual nos enardecemos (Rep. 4.439e5-6) y enojamos, pero también es la parte por la que disfrutamos del predominio, la victoria y el renombre por lo que también se denomina ambiciosa y amante de los honores (9. 581b2-3). En función del paralelismo por el que apuesta Platón a lo largo de toda República entre los planos psíquico y social, el predominio de un tipo de organización anímica en una comunidad determina su modelo político; así, en las monarquías o aristocracias encontramos hombres gobernados por la razón, en las timocracias por la impulsividad y en las oligarquías, democracias y tiranías hombres llevados por los apetitos (Rep. VIII y IX).

No es difícil inclinarse a identificar a Alcibíades con el hombre tiránico, pues el relato dramático de las afrentas sufridas por su amor no correspondido en Banquete destaca dos señales inconfundibles del tirano: el amor que gobierna su alma por sí solo, es decir, en completa anarquía y anomia y que lo lleva a cometer todo tipo de audacias y excesos (Rep. 9. 574e333-575 a4) y el dominio de los apetitos (epithymiai) que, por naturaleza, por hábito o por ambas cosas a la vez lo tornan borracho, erótico o lunático (Rep. 9. 573c8-10). Precisando un poco más esta analogía entre Alcibíades y el tirano Bieda (2016) propone la figura del proto-tirano que se halla en un estado de 
transición entre un pasado democrático ${ }^{20}$ y un futuro tiránico; el conflicto interno que presenta el general ateniense entre el amor por los placeres sensibles y los honores y al mismo tiempo el reconocimiento del valor de la vida filosófica que profesa y practica Sócrates, da cuenta que conserva en su interior deseos nobles que perduran de su pasado democrático y que explican su amor y reconocimiento de la belleza de Sócrates (219d3-e1) que entran en contradicción con deseos viles producto de la transición a la tiranía.

Hay un elemento determinante para reconocer este lugar intermedio o de transición de Alcibíades: la vergüenza (aischynesthai hontinoun) que el proto-tirano siente ante los otros por sus actitudes arrebatadas y determinadas por los apetitos ya que de alguna manera se da cuenta de su falta, aunque no pueda controlarla. $Y$ es Sócrates quién le hace sentir vergüenza,

\footnotetext{
únicamente ante él siento vergüenza, porque me doy perfecta cuenta que no puedo negar que hacer lo que él exhorta hacer es una necesidad. Pero no bien me alejo de él, sucumbo ante el reconocimiento que me tributa el vulgo (216b2-6).
}

Ahora bien, en las reiteradas ocasiones que Alcibíades muestra preocupación por la vergüenza o deshonra que puede sufrir $(217 d 3 ; 218 d 4 ; 219 c 4)$, ¿qué significa sentir vergüenza o a qué se lo podríamos atribuir? Por vergüenza (aischynesthai) se puede entender la deshonra o mala reputación como el sentimiento que se genera en el sujeto por este motivo; es a lo que cualquier ser humano rehúye porque padecerla significa alejarse de bello y bueno y acercarse a lo feo (aischron) y alejarse de la estima de los demás. En cuanto a su procedencia, según el esquema psicológico de Platón, de un lado, la vergüenza puede provenir de la parte racional del alma que la activa para indicar lo incorrecto de los deseos. Cuando durante el sueño la razón está apagada y se enciende la parte bestial y salvaje "el alma se atreve a todo, como si estuviera liberada y desembarazada de toda vergüenza y prudencia..." (Rep. 9. 571c8-9); sin embargo, si

${ }^{20}$ La democracia si bien no es un régimen estimable para Platón, conserva algunos rasgos positivos en tanto hace convivir distintos tipos de deseos e inclinaciones (Rep. 8. 555b45616). 
es el caso de una acción incontinente $(a k r a s i a)^{21}$ la vergüenza funciona como una consecuencia o efecto de conocer lo correcto pero no poner llevarlo a cabo en la acción.

Si analizamos las acciones de Alcibíades en este contexto debemos asumir que su capacidad de reconocer las virtudes de Sócrates implica un trabajo de la razón para distinguir lo bueno y correcto, pero también es cierto el hecho de que esto queda en segundo plano frente a otros aspectos que se dejan ver en su discurso como el enojo, los celos, el reproche y la importancia de la mirada de los demás. Por ello, es preciso considerar que la vergüenza también procede de la parte timócrata o irascible del alma que, preocupada por la fama y los honores, teme frente a la desaprobación social de sus acciones. Alcibíades sufre al sentirse deshonrado por Sócrates por la falta de reconocimiento de sus cualidades y su preocupación por la deshonra es tal que, incluso cuando es llevado intensamente por la pasión erótica a buscar a Sócrates, evitar exponerse y mostrar debilidad; según su relato, él hace todo lo posible por generar un ambiente propicio para poder intimar con Sócrates (217b3-219d4), pero en ningún momento vuelve explícitas sus intenciones porque no quiere mostrarse él como el enamorado. Incluso, en el momento que es más directo, sigue intentando que sea Sócrates el que reconozca su deseo sexual.

\footnotetext{
Pienso que tú -le dije- eres el único digno de convertirse en mi amante. Pero me parece que te da vergüenza hablarme de eso. En lo que me toca, este es mi parecer. Considero que sería muy tonto no complacerte en esto, e incluso si necesitas algo de mi fortuna o de la de mis amigos. Nada es más importante para mí que llegar a ser tan excelente como sea posible; y considero que, para lograr esto, nadie puede ayudarme mejor que tú. [y nuevamente trae a escena el problema de la vergüenza cuando continuando diciendo] Por eso, yo me avergonzaría mucho
}

${ }^{21}$ La akrasia o incontinencia se refiere al actuar de forma incorrecta o haciendo algo que es dañino para uno mismo teniendo la certeza interna de lo que es correcto. En el esquema platónico de la tripartición y oposición de las partes del alma la acción incontinente implicaría que los apetitos logren imponerse por sobre lo determinado por la razón y la vergüenza se presenta porque aunque el agente sabe lo que es correcto, prefiere saciar su parte apetitiva o es llevado con más fuerza por ésta. Sobre el problema del conocimiento del bien y la acción vid. Boeri, 2007. 
más frente a las personas sabias por no complacer a un hombre así que frente a una muchedumbre de necios por complacerlo (218c5-d7).

No quiere pasar vergüenza, no quiere que lo señalen, no quiere perder el respeto de los otros.

Para los griegos, la cuestión del honor tenía vital importancia principalmente en los jóvenes, porque aseguraba su inserción en el tejido social, con el matrimonio en el caso de las mujeres y con el lugar en la polis en el caso de los varones (vid. Calame, 2002; Foucault, 2003). De manera que evitar la vergüenza pública, cuidando la propia conducta y la apreciación que de esta puedan hacer los demás, tiene un interés político evidente que es el de garantizar el apoyo del pueblo que, junto con las condiciones de estatus, estirpe, riquezas que de cuna portan estos jóvenes, posibilita el acceso al poder. El protagonismo de un sentimiento como la vergüenza refuerza la tesis de que lo más saliente en el personaje de Alcibíades es la preocupación por la mirada de los demás, de la necesidad de aprobación, reconocimiento y respeto. En este sentido, un predominio de la búsqueda y preservación de honores nos permite suponer que su alma está dominada por to thymoeides y no principalmente por los apetitos como en el caso del tirano. Veamos entonces cómo funciona esta parte del alma y cómo configura al individuo en el cual predomina.

\section{El alma timocrática de Alcibíades}

Caracterizar a to thymoeides como un aspecto del alma resulta un tanto problemático para cualquier lector por sus múltiples usos dentro de República ${ }^{22}$, pero también lo es incluso para el mismo Platón ya que esta fuente de deseo no tiene $a$ priori una dirección completamente definida sino que tensiona entre lo racional y lo apetitivo. Lo más saliente es su tendencia a manifestarse mediante la ira o cólera (Rep. $4.441 b)$ y a alimentarse con los honores y la fama, por eso también se lo llama

${ }^{22}$ El término thymos cuenta con múltiples significados en la lengua griega y a lo largo de República Platón evoca diferentes significados (agresividad, cólera, deseo de fama y honores, indignación moral, perseverancia en las opiniones, coraje intelectual); sin embargo, atendiendo a nuestro interés de fundamentar el perfil de Alcibíades como un hombre timocrático, solo tomamos la acepción del libro VIII que aborda to thymoeides en relación a la polis. Para ampliar los significados ver Fierro (2011). 
"amante de la victoria" (philonikon) o "amante del honor" (philotimon) (Rep.9.581 a10b3). En una organización anímica donde predomina to thymoeides lo más manifiesto es el deseo de imponerse y ser venerado (Rep. 9.548c4-6) convirtiendo al hombre en un timócrata. La particularidad del perfil timocrático es que en su interior el bien y el mal se hallan mezclados (Rep. 8. 548c3-4), producto de tener una naturaleza buena y ser criado por un buen padre pero vivir en un Estado mal organizado:

Entonces el joven que oye y ve todo esto, pero a su vez oye las palabras de su padre y ve sus preocupaciones de cerca y las compara con las de los demás, es arrastrado en ambas direcciones, por su padre, que irriga y hace crecer lo que de racional hay en su alma, y por los demás, que cultivan lo apetitivo y lo fogoso; y en razón de no ser mal hombre por naturaleza sino de andar en malas compañías, al ser arrastrado en ambas direcciones, llega a un compromiso, y ofrece el gobierno de sí mismo al principio intermedio ambicioso y fogoso, y se convierte en $\mathrm{u} n$ hombre altanero y amante de los honores (Rep. 8. 550 a5-b8).

Esta formación mixta del timocrática se corresponde con el carácter bivalente de la corriente de deseo de to thymoeides (Fierro,2011) que, en tanto impulso, se aproxima a la parte irracional/apetitiva que tiende imponer sus deseos y a afirmarse irreflexivamente, pero al mismo tiempo también puede convertirse en un aliado de la razón y canalizar todo su potencial para mantenerse firme en lo que ésta dictamina como lo correcto. De manera que se encuentra en el medio de lo racional y lo apetitivo, sin identificarse a priori con ninguno de ellos, y potencialmente puede aliarse con cualquiera de los dos; en este punto, la educación es el elemento definitorio que va a determinar si to thymoeides se subordina a la razón o se deja llevar por los apetitos (Rep. 4. 441e4-442a3). Lo natural, dice Platón, es que to logistikon y to thymoeides trabajen aliadas y luchen contra los apetitos (Rep. 4.441 a), para que el hombre sea dueño de sí mismo dominando los enemigos internos y, además, valiente y victorioso en lucha contra los enemigos externos. Pero si to thymoeides no logra controlarse y se aleja de la razón, su impetuosidad y deseo de fama y honores hace que el hombre busque imponerse y afirmarse frente a los otros sin consideración de lo que es correcto. 
Con respecto a su facultad moral es autónoma y claramente no racional. To thymoeides forma parte del aspecto irracional del alma pero tiene parámetros propios para captar el valor o calidad de sus actos, los cuales están sujetos a la aprobación o desaprobación por parte de la mirada de los demás. Esto queda claro cuando Leoncio, caso paradigmático que utiliza Platón para describir al hombre irascible, frente al impulso de contemplar los cadáveres siente cólera por no poder reprimirse y ceder (Rep. 439e-440a). La cólera que experimenta es producto de la vergüenza que le produce realizar un acto que por ser morboso y desagradable, sería repudiado por los demás ${ }^{23}$. "Leoncio no pone en juego si mirar los cadáveres es algo moralmente bueno o malo desde el punto de vista de lo que tiene por justo o bueno-parámetro racional-, sino el hecho de que mirarlos le reportará un deshonor social y personal parámetro timótico-. No se trata, así, de una acción incontinente sino de una acción deshonrosa" (Bieda, 2012, p. 145).

Establecida la autonomía de su capacidad desiderativa y moral y la potencialidad de aliarse con la razón y con los apetitos, resta preguntarnos qué representa la philotimia o amor por los honores de Alcibíades en el contexto del Banquete, si tiene un valor positivo o negativo para el desarrollo su relación con Sócrates y en qué medida puede realizar algún aporte. De un lado, la philotimia puede interpretarse como el fracaso de las enseñanzas y consejos de Sócrates que pretendían mostrarle a su discípulo la importancia del ocuparse de sí mismo y lograr el autogobierno como preparación previa y necesaria antes de ocuparse de los asuntos políticos. Alcibíades, consciente de su fracaso, llega a sentir que lleva una vida indigna (215e10), "pues me fuerza a reconocer que a pesar que me falta mucho [para llegar a ser un hombre noble y bueno], no me ocupo de mí...y atiendo los asuntos de los atenienses" (216a5-8). De manera que la philotimia reviste un carácter negativo para Alcibíades porque por, un lado, lo aleja de Sócrates y de sus consejos y, por otro lado, lo lleva a avergonzarse por su debilidad ante los tributos del vulgo (Cornelli, 2012). Santas (2010).

${ }^{23}$ Vid. Cooper (1984), Davidson (2001), Reeve (2004), Brickhouse y Smith (2010) y 
Pero los efectos de philotimia en el erōs de Alcibíades también pueden tener una carga distinta, no completamente negativa. Según las palabras de Diotima citadas en el primer parágrafo de este escrito, hemos visto que los hechos realizados por philotimia están motivados por la búsqueda de inmortalidad, aunque sus efectos solo se circunscriban al plano terrenal, y tienen un contacto necesario con lo bello, tanto en su génesis (porque es en la vinculación con las cosas y personas bellezas que pueden engendrar belleza) como sus efectos (bellos discursos, poemas, leyes, etc.). Recordemos que en el camino que realiza el iniciado en los misterios de erōs la sensibilidad frente a la belleza del amado, siendo más digna la belleza anímica que la corporal, es suficiente para procurar el deseo en el amante y la disposición para ocuparse del joven, para dar a luz y buscar los razonamientos que lo vuelvan mejor (210c1-2); ocuparse de la belleza en los discursos y en los modos de vida, para educar y cuidar al amado, pero también para que sean apreciados y aprovechados por otros, constituyen la instancia preparatoria para acceder al amor a la sabiduría. En este sentido, el carácter positivo de la philotimia está dado por su relación con la belleza, por su carácter propedéutico en el ascenso amoroso $y$, fundamentalmente, por considerar la presencia e importancia de los otros en la necesidad de permanecer en la memoria colectiva; la philotimia predispone al desarrollo de la virtud personal que queda plasmada en las producciones poéticas y legislativas que luego resultan útiles como modelos de conducta y formas de vida para una comunidad.

Para Larsen (2013) la philotimia que manifiesta el discurso de Alcibíades no podría encuadrarse en el deseo de inmortalidad del que habla Diotima ${ }^{24}$, puesto que no está interesado por los honores de la multitud sino en parecer respetable antes Sócrates, su amado, de manera que la productividad de su philotimia sería solo individual, el parámetro para el desarrollo de un alma virtuosa es el amado y nadie más. En cambio, en la propuesta de la sacerdotisa la philotimia está conectada con la

${ }^{24}$ La philotimia con sesgo más "individualista" se acerca a la definición que ofrece Fedro en Banquete de la misma que también resulta como consecuencia de erōs, pero restringido a la relación entre los amantes. El desarrollo de la virtud y la honorabilidad se busca en la mirada del amante y por eso en los casos vergonzosos o indignos la vergüenza se siente frente al amante y no frente a la familia o los amigos (178e). 
El eros de Alcibíades. Entre Sócrates y la philotimia

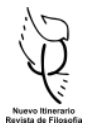

esfera política ya que motiva la producción de leyes y poemas que sirven a todos. Sin embargo, es posible considerar que la philotimia de Alcibíades no se reduce solo a Sócrates, puesto que si bien él declara que sólo ante Sócrates siente vergüenza, como hemos demostrado en las páginas anteriores, Alcibíades no solo se preocupa por la mirada de Sócrates sino también por la del resto de los asistentes del banquete y la multitud en general que es lo que lo constituye como político.

\section{Conclusión}

Sintetizando los aspectos de Erōs tratados en el discurso de Sócrates encontramos que su condición de daimōn y de naturaleza metaxy hace de la pasión amorosa un deseo dinámico, porque está en permanente búsqueda de aquello que no posee; relacional, porque vincula estados o condiciones (ignorancia/conocimiento, fealdad/belleza) y planos de realidad (humano y divino), y, por último, una aspiración a la inmortalidad, que tiene dos niveles de concreción, terrenal y divina. Asimismo, el deseo erótico es universal y neutral, y podemos encontrar su positividad o negatividad en función de los efectos que produce la tensión hacia el objeto deseado para el amante. En este sentido, analizamos los efectos que produce la philotimia en Alcibíades y encontramos que no es una pasión completamente irracional, pues la parte to thymoeides del alma tiene la capacidad de generar opiniones a partir de parámetros propios que regulan lo que es conveniente hacer y lo que no en función de la aprobación de los demás. El hecho de que Alcibíades regule sus acciones en función de la mirada de los demás quizás permita que se convierta en un hombre virtuoso, pero la realización de su erōs queda atrapada en una inmortalidad terrenal, garantizada por la memoria de los seres humanos y generada por la complacencia de estos, lo cual no necesariamente está fundamentado en lo verdaderamente correcto.

Sin embargo, esta forma política de amar tiene su aspecto positivo. En primer lugar, hace que Alcibíades se preocupe por realizar acciones virtuosas no solo para la 


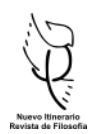

mirada de su amado sino para la mirada de todos. En segundo lugar, los productos de esas acciones virtuosas pueden ser beneficiarias para la comunidad, como discursos sobre la virtud que eduquen a los ciudadanos o buenas legislaciones para la polis. En tercer lugar, y este es el punto que más nos interesa destacar, los efectos de la philotimia de Alcibíades podrían no recaer solamente en él sino también en su amado, Sócrates, y de esta manera generar una apertura en lo que significa el proceso de transformación de sí mismo en el desarrollo de una erótica que tienda a la inmortalidad divina.

En conclusión, la concepción del erōs platónico que se desprende del análisis de la relación entre Sócrates y Alcibíades remite a una complementación entre el amante del saber o filósofo y el amante político. El filósofo muestra al político la importancia de alcanzar la sabiduría y político aporta la necesidad de contemplar el bien común en la persecución del bien propio o del desarrollo de la propia virtud. De este modo, en el proceso erótico pueden mimetizarse las funciones, el político se vuelve filósofo para que las decisiones que tome en pos del bien común sean las mejores y con los mejores resultados y el filósofo se vuelve político para que su contacto con la verdad tenga un sentido más allá de propia transformación.

\section{Bibliografía}

1. Alegre Gorri, A (2010). Introducción. En: Platón. Diálogos I. Gredos, Madrid.

2. Álvarez Lacruz (2006). El amor: de Platón a hoy. Madrid: Palabra.

3. Bieda, E. (2012). ¿Es Leoncio un incontinente? Ira y apetito en la República de Platón, Diánoia, volumen LVII, número 69 (noviembre 2012), 127-150.

4. Bieda, E. (2016). "El alma tiránica de Alcibíades en el Banquete". En Ágora. Papeles de filosofía, 149-170.

5. Boeri, M. (2007). Apariencia y realidad en el pensamiento griego. Investigaciones sobre aspectos epistemológicos, éticos y de teoría de la acción en algunas teorías de la Antigüedad. Buenos Aires: Colihue. 


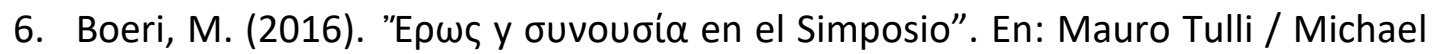
Erler (eds.). Plato in Symposium. Sankt Augustin: Academia Verlag. 362-371.

7. Borges de Araújo Jr., A. (2012) Eros: direzione e effetti. En: // Simposio di Platone: un banchetto di interpretazioni. Anastácio Borges de Araújo Jr. y Gabriele Cornelli (Comp.). Napoli: Loffredo, 15-3.

8. Calame, C. (2002). Éros en la antigua Grecia. Madrid: Akal.

9. Cornelli, G. (2012) La colpa di Alcibiade. En: // Simposio di Platone: un banchetto di interpretazioni. Anastácio Borges de Araújo Jr. y Gabriele Cornelli (Comp.). Napoli: Loffredo, 77-94.

10. Cornford, F.M. (1974).La doctrina de Eros en el Banquete de Platón. En La filosofía no escrita y otros ensayos. Barcelona: Ariel, 68-81.

11. Dover, K. J. (2008). Homosexualidad griega. Barcelona: El cobre.

12. Eggers Lan, C. (2011) (Trad.) República. Madrid: Gredos.

13. Eggers Lan, C. (2000). Introducción histórica al estudio de Platón. Buenos Aires: Colihue.

14. Fierro, M. (2006). Platón y los privilegios de los amantes, en Noua tellus, 24 v.2, 167-195.

15. Fierro, M. (en prensa). Introducción. En: Platón. Fedro. Traducción, notas, introducción y comentario: María Angélica Fierro, Colihue, Bs. As..

16. Fierro, M.A. (2007). El concepto filosófico de metaxŷ en el Banquete de Platón. En: J. Martínez Contreras (ed.), El saber filosófico, México, 249-254.

17. Foucault, M. (2008). Historia de la sexualidad II: el uso de los placeres. Trad. Martí Soler. Siglo XXI: Buenos Aires.

18. Foucault, M. (2011). La hermenéutica del sujeto. Curso en el College de France (1981-1982). Trad. Horacio Pons. México: Fondo de Cultura Económica.

19. Guthrie, W.K.C. (1984). Historia de la Filosofía Griega I-VI. Madrid: Gredos.

20. Larsen, K. (2013). Philotimia and Philosophia in Plato's Symposium. (Presentado en el X Symposium Platonicum: Plato's Symposium, Pisa, Italia, Julio de 2013; no publicado).

21. Ludueña, E. (2015) (Trad.) Banquete. Buenos Aires: Colihue. 
22. Ludueña, E. (2015). Introducción. En: Platón. Banquete. Trad. Ezequiel Ludueña, Buenos Aires: Colihue.

23. Ludwig, P. W. (2002). Eros and polis. Desire and Community in Greek Political Theory. New York: Cambridge University Press.

24. Marrou H.E. (1971). Historia de la educación en la antigüedad. Madrid: Eudeba.

25. Nussbaum, M. (1995). La fragilidad del bien. Fortuna y ética en la tragedia y la filosofía griega. Madrid: Visor.

26. Peñalver, P. (2000). Dos dogmas del antiplatonismo. Daimon: Revista de Filosofía 21, 107-206.

27. Santa Cruz, M. I. \& Crespo, M. I. (2007) (Trad.) Platón. Fedro. Buenos Aires: Losada.

28. Soares, L. (2009). La erótica platónica en perspectiva. Notas para una lectura del Banquete (Estudio preliminar). En: Platón. Banquete, trad. de Claudia Mársico. Buenos Aires: Miluno, 2009, 13-128.

29. Soares, L. (2010). Platón y la política. Madrid: Tecnos.

30. Soares, Lucas (2011). La dimensión práctica del saber erótico de Sócrates, Classica. Revista Brasileira de Estudos Clássicos, 24, 1/2, 2011, 22-34.

31. Soto Comené, P. (2011). Lo político en la sabiduría del proceso al saber de Eros en El Banquete de Platón. Santiago de Chile: Universidad de Chile. Facultad de Filosofía y Humanidades. Escuela de Postgrado. Tesis para optar al grado de magister en Filosofía.

32. Vlastos, Gregory. (1981). The individual as an object of love in Plato. En Platonic Studies. Princeton: Princeton University Press, 3-42. 